Check for updates

Cite this: RSC Adv., 2017, 7, 21749

Received 8th February 2017

Accepted 10th April 2017

DOI: $10.1039 / c 7 r a 01606 a$

rsc.li/rsc-advances

\section{Biosilicate scaffolds for bone regeneration: influence of introducing SrO}

\author{
Cijun Shuai, ${ }^{\text {abc }}$ Hang Sun, ${ }^{a}$ Ping Wu, ${ }^{d}$ Chengde Gao, ${ }^{a}$ Youwen Yang, ${ }^{\text {ac }}$ Wang Guo, ${ }^{a}$ \\ Dafeng Yang, ${ }^{e}$ Feng $X u,{ }^{e}$ Pei Feng ${ }^{* a}$ and Shuping Peng (D)*fgh
}

Strontium (Sr), a bioactive element in natural bone, plays a crucial role in stimulating bone remodeling and inhibiting bone resorption. In this study, strontium oxide ( $\mathrm{SrO}$ ) was incorporated into biosilicate $\left(\mathrm{Mg}_{2} \mathrm{SiO}_{4} /\right.$ $\mathrm{CaSiO}_{3}$ ) scaffolds to improve the biological properties. The results revealed that $\mathrm{SrO}$ significantly enhanced cell adhesion, proliferation and the alkaline phosphatase (ALP) activity of the scaffolds. It could be explained that $\mathrm{Sr}^{2+}$ can stimulate osteoblast-related gene expression (osteocalcin, type I collagen, Runx2, etc.) and inhibit osteoclast differentiation. Moreover, the doped scaffolds could degrade continuously and form a dense apatite layer in SBF (simulated body fluid). Besides, the doped scaffolds possessed stable mechanical properties. However, excessive $\mathrm{SrO}$ led to a decrease in the strength of the scaffolds, which could be ascribed to the occurrence of unit cell volume expansion caused by the substitution of $\mathrm{Sr}^{2+}$ for $\mathrm{Ca}^{2+}$ in the $\mathrm{CaSiO}_{3}$ lattice. Our research indicated that the SrO doped biosilicate scaffolds have great potential for application in bone regeneration.

\section{Introduction}

Forsterite $\left(\mathrm{Mg}_{2} \mathrm{SiO}_{4}\right)$, a $\mathrm{Mg}$-containing silicate bioceramic, has shown great potential as a biomaterial for bone repair/ regeneration owing to its suitable cytocompatibility and mechanical properties..$^{1-3}$ Meanwhile, $\mathrm{Si}$ and $\mathrm{Mg}$ are involved in the bone calcification process. ${ }^{\mathbf{4} 5}$ However, the poor degradability and apatite formability limited its further application. ${ }^{6,7}$ Wollastonite $\left(\mathrm{CaSiO}_{3}\right)$, a Ca-containing silicate bioceramic, possesses fast degradability and excellent apatite formability, which can be used to improve the bioactivity of forsterite. Furthermore, it can also improve the mechanical properties of forsterite acting as a filling reinforcement phase. ${ }^{8-12}$ Nevertheless, the osteogenic capacity of

${ }^{a}$ State Key Laboratory of High Performance Complex Manufacturing, Central South University, Changsha, Hunan 410083, China. E-mail: fengpei@csu.edu.cn; Fax: +86731-88879044; Tel: +86-731-84805412

${ }^{b}$ State Key Laboratory for Powder Metallurgy, Central South University, Changsha, Hunan 410083, China

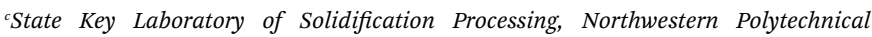
University, Xi'an, Shanxi, 710072, China

${ }^{d}$ College of Chemistry, Xiangtan University, Xiangtan, Hunan 411105, China

${ }^{e}$ Hunan Farsoon High-Technology Co. Ltd, Changsha, Hunan 410205, China

${ }^{f}$ The Key Laboratory of Carcinogenesis of the Chinese Ministry of Health, Xiangya Hospital, Central South University, Changsha, Hunan 410008, China. E-mail: shuping@csu.edu.cn; Fax: +86-731-8887-9044; Tel: +86-731-8887-9351

${ }^{g}$ The Key Laboratory of Carcinogenesis and Cancer Invasion of the Chinese Ministry of Education, Cancer Research Institute, Central South University, Changsha, Hunan 410078, China

${ }^{h}$ Hunan Key Laboratory of Nonresolving Inflammation and Cancer, Disease Genome Research Center, The Third Xiangya Hospital, Central South University, Changsha, Hunan 410078, China the composite silicates was insufficient to meet the requirements of clinical applications. Incorporation of trace minerals like $\mathrm{Na}$, $\mathrm{Mg}, \mathrm{Ti}, \mathrm{Ag}, \mathrm{Zn}$ and $\mathrm{Sr}$ in biomaterial can significantly improve the biological properties. ${ }^{13-16}$

Strontium ( $\mathrm{Sr}$ ) as a bioactive trace element in human bone has drawn significant scientific interest due to its dual effects of stimulating new bone formation and inhibiting bone resorption in the bone remodeling process. It was because Sr not only can stimulate osteoblast-related gene expression and the alkaline phosphatase (ALP) activity but also can inhibit the differentiation of osteoclasts. ${ }^{17-21}$ Stevens et al. developed Sr-substituted bioactive glass (Sr-BG), created a biomaterial with the improved osteoblast proliferation and ALP activity for bone repair/regeneration. ${ }^{22,23}$ Bose et al. found that the SrO doping in $\beta$-TCP promoted the cell attachment, proliferation, ALP activity and expression levels of osteocalcin and type I collagen. ${ }^{24} \mathrm{Lu}$ et al. prepared strontiumcontaining hydroxyapatite (Sr-HA) cement and found that the presence of $\mathrm{Sr}$ could significantly stimulate bone formation and osteoporotic bone regeneration. ${ }^{25}$

In addition to chemical composition, an interconnected porous structure in scaffolds can mimic architecture and function of the extracellular matrix, as well as provide a pathway for intercellular communication, the exchange of nutrient and waste and ingrowth of cell and vascular. ${ }^{26,27}$ Many methods including phase separation, electrospinning, gel casting and porogen techniques had been utilized to prepare porous scaffolds for bone tissue engineering applications. ${ }^{28-30}$ However, these methods were difficult to precisely control the pore size and porosity, which directly influence scaffolds' interconnectivity, mechanical strength, and in vivo bone-formation ability. Selective laser sintering (SLS) constructed 
the scaffolds layer-by-layer as designed and could offer precise control over the pore size, porosity and interconnectivity as well as the accurate external geometries. ${ }^{31,32}$ These features make SLS an ideal technology for scaffolds fabrication.

In this study, $\mathrm{SrO}$ was introduced into $\mathrm{Mg}_{2} \mathrm{SiO}_{4} / \mathrm{CaSiO}_{3}$ scaffolds by SLS to improve the biological properties. The influences of $\mathrm{SrO}$ on cellular response, degradability and bioactivity were studied by using MG-63 cells culture and SBF immersion. Meanwhile, microstructure and mechanical properties of the biosilicates scaffolds were also evaluated.

\section{Materials and methods}

\subsection{Materials}

$\mathrm{Mg}_{2} \mathrm{SiO}_{4}$ with a mean particle size of about $5 \mu \mathrm{m}$ was derived from Alfa Aesar China Co., Ltd. (Tianjin, China). $\beta-\mathrm{CaSiO}_{3}$ with a diameter ranging from $0.2-2 \mu \mathrm{m}$ was provided by Kunshan Huaqiao New Materials Co., Ltd. (Kunshan, China). SrO powder with particle size ranging from 5 to $20 \mu \mathrm{m}$ was supplied by Changsha Weixi New Materials Technology Co., Ltd. (Changsha, China). All the above reagents were of analytical grade ( $\geq 99.9 \%$ purity).

$\mathrm{Mg}_{2} \mathrm{SiO}_{4}$ and $\mathrm{CaSiO}_{3}$ powders were mixed at an $8: 2$ mass ratio, and then ultrasonicated in ethanol for $30 \mathrm{~min}$. Subsequently, the mixtures were mixed with anhydrous ethanol and $\mathrm{ZrO}_{2}$ balls for $2 \mathrm{~h}$ of wet ball mill grinding at $30 \mathrm{rpm}$. Next, the mixed powders were dried at $70{ }^{\circ} \mathrm{C}$ for $12 \mathrm{~h}$ in drying cabinet. After that, a certain mass ratio of $\mathrm{SrO}(0 \mathrm{wt} \%, 0.5 \mathrm{wt} \%, 1.0 \mathrm{wt} \%, 2.0 \mathrm{wt} \%$ and $3.0 \mathrm{wt} \%$ ) were added into the dried powders and followed by $30 \mathrm{~min}$ of hand grinding. Finally, a series of $\mathrm{SrO}$ doped $\mathrm{Mg}_{2} \mathrm{SiO}_{4} /$ $\mathrm{CaSiO}_{3}$ mixed powders, which were named 0SrO, 0.5SrO, 1SrO, $2 \mathrm{SrO}$ and $3 \mathrm{SrO}$, were produced for scaffold fabrication.

\subsection{Scaffold fabrication}

Scaffolds were fabricated by using SLS (selected laser sintering) technique. The SLS system was consisted of a $100 \mathrm{~W} \mathrm{CO}_{2}$ laser, an $x-y-z$ motion sintering platform and corresponding control system..$^{33}$ During sintering, the laser beam selectively sintered the powders layer by layer based on the cross-sectional area of the designed scaffold. All the sintering parameters were maintained constant with the following values: laser spot diameter of $1.0 \mathrm{~mm}$, scan line interval of $3.5 \mathrm{~mm}$, layer thickness of 0.1-0.2 $\mathrm{mm}$, laser power at $8.5 \mathrm{~W}$ and scan speed at $100 \mathrm{~mm} \mathrm{~min}^{-1}$.

\subsection{Characterization}

The phase analysis of the SrO doped and undoped scaffolds was performed by X-ray diffraction (Rigaku Co., Tokyo, Japan) with copper target, $\mathrm{K} \alpha \mathrm{X}$-ray at $30 \mathrm{kV}$ and $35 \mathrm{~mA}$, and Ni filter. Each $\mathrm{XRD}$ data was obtained over the $2 \theta$ range of $10-80^{\circ}$ at a steplength of $0.02^{\circ}$ and a step-interval of 0.2 s. Surface morphologies of the scaffolds were visualized under SEM (Tescan Mira3 Lmu, Co., Czechia) equipped with EDS (energy dispersive spectroscopy). Prior to SEM observation, all scaffold samples were polished, thermally etched for $30 \mathrm{~min}$ at $1250{ }^{\circ} \mathrm{C}$ and platinum-sputtered (JFC-1600, Jeol Co., Japan).

Compression strength of the scaffolds $\left(18.5 \times 18.5 \times 6.5 \mathrm{~mm}^{3}\right)$ with various $\mathrm{SrO}$ dopants was tested under an electron universal testing machine (Shanghai Zhuoji Instruments Co., Ltd., Shanghai, China) with a crosshead speed at $0.5 \mathrm{~mm} \mathrm{~min}^{-1}$. The stress-strain data were collected and recorded until compression fracture occurred, and the ultimate compressive strength was calculated as: maximum load/original cross-sectional area (five scaffolds were tested). Fracture toughness $\left(K_{\mathrm{IC}}\right)$ was tested on a Vickers microindenter (Shanghai Taming Optical Instrument Co., China). A $4.98 \mathrm{~N}$ load, derived from a pyramid shaped diamond indenter, was loaded on polished surface of the scaffolds. And the load lasted for 10 seconds to induce indentations and cracks. Then the ultimate fracture toughness could be calculated according to the following eqn (1): ${ }^{34}$

$$
K_{\mathrm{IC}}=0.0824 P \times C^{-3 / 2}
$$

where $P$ is the applied indentation load $(\mathrm{N})$ and $C$ is half of diagonal crack length $(\mathrm{m})$. The average values were measured from 10 indents on each scaffold.

\subsection{Mineralization and degradation}

To evaluate the bioactivity and degradation of the scaffolds, SBF with inorganic ion components approximately equal to those of human blood plasma was prepared according to Kokubo et al. method. ${ }^{35}$ All the scaffolds were immersed in SBF $(\mathrm{pH}=7.4)$ with a solid/liquid ratio of $0.1 \mathrm{~cm}^{2} \mathrm{~mL}^{-1}$ in a thermostat $\left(37^{\circ} \mathrm{C}\right)$ for 7 and 14 days. During the process of the immersion, the SBF solution was refreshed once every two days. At each predetermined time, the scaffolds were taken out, carefully rinsed with double distilled water, dried in drying oven at $70{ }^{\circ} \mathrm{C}$ and then weighted. The weight loss percentage was calculated as: $100 \times$ [weight loss/weight before immersion]. In addition, the immersed scaffolds were also platinum sputtered and observed using SEM equipped with EDS to determine the formation of the apatite. Moreover, the surface chemical functional groups and phase composition of the scaffolds were examined by using FTIR (Fourier transform infrared spectroscopy) (Thermo Electron Scientific Instruments, USA) and XRD to further determine the formation of apatite. Besides, the ion concentrations of $\mathrm{Ca}$, $\mathrm{Sr}, \mathrm{Mg}, \mathrm{P}$, and Si ions in SBF after the immersion of the $1.0 \mathrm{wt} \%$ SrO doped scaffolds were measured $(n=3)$ by inductively coupled plasma atomic emission spectroscopy (ICP-OES; Perkin Elmer, Optima 5300DV, USA).

\subsection{Cell culture}

The cytocompatibility assessment of the scaffolds was performed by using MG-63 osteoblast-like cell (American Type Culture Collection, Rockville, USA). Fetal bovine serum (FBS) and Dulbecco's modified Eagle's medium (DMEM) were purchased from Cellgro-Mediatech Inc. (Manassas, VA, USA). Dimethyl sulfoxide (DMSO), calcein-AM and MTT (3-(4,5dimethylthiazol-2-yl)-2,5-diphenyl tetrazolium bromide) were supplied by Sigma-Aldrich (St. Louis, MO, USA). And the other cell culture related reagents were obtained from Life Technologies (Eggenstein, Germany).

The cell line was cultured in DMEM containing $10 \mathrm{vol} \%$ fetal bovine serum (FBS) and 5\% penicillin/streptomycin antibiotics at 
$37{ }^{\circ} \mathrm{C}$. Before cell seeding, all the scaffolds were cleaned using $70 \%$ ethyl alcohol solution, and washed again with PBS after $30 \mathrm{~min}$ of ultraviolet light sterilization. After that, cells were seeded at a density of 35000 cells per well onto the scaffolds and cultured in 12-well plates for 1, 3 and 5 days. The media were maintained at $37{ }^{\circ} \mathrm{C}$ in a humidified atmosphere and refreshed once every two days. Three parallel samples were fostered for each group. At predetermined culture time point, the scaffolds were taken out, rinsed with PBS and fixed with modified Karnovsky's fixative in PBS for one hour. Following this, the scaffolds were successively dehydrated in graded ethanol (70\%, 80\%, 90\%, $100 \%$ ). Finally, the scaffolds were platinum-sputtered and visualized under SEM to examine the cell-scaffold interactions.

Additionally, fluorescence technique was applied to investigate the cell-scaffold interactions. After culture, cell culture media were removed, cells were washed twice with phosphate buffered saline (PBS) and incubated in PBS containing $4 \mathrm{mM}$ calcein $\mathrm{AM}$ for 30 minutes at $37^{\circ} \mathrm{C}$. After staining, the cells were washed twice again with PBS. Finally, the cells were visualized under confocal microscope.

MTT (3-(4,5-dimethylthiazol-2-yl)-2,5-diphenyl tetrazolium bromide) assay was performed to evaluate cell viability and proliferation. At indicated time points, $200 \mathrm{~mL}$ DMEM with supplement $20 \mathrm{~mL} 5 \mathrm{mg} \mathrm{mL}{ }^{-1}$ MTT solution was added to each scaffold and incubated at $37{ }^{\circ} \mathrm{C}$ for $4 \mathrm{~h}$ to form MTT formazan. After that, the medium was removed, and $200 \mathrm{~mL}$ dimethyl solubilization was added into each cell to dissolve the formazan crystals. Finally, the optical density (OD) was recorded by using an enzyme immunosorbent assay reader at $570 \mathrm{~nm}$. The average OD value was obtained from three scaffold data for each group.

Furthermore, to evaluate the differentiation capability of the MG-63 cell after cultured on the scaffolds. ALP staining was performed to evaluate the alkaline phosphatase (ALP) activity. At indicated time points, the adherent cells were removed, washed three times with PBS, and mixed with cell lysis buffer containing $0.1 \%$ Triton $\mathrm{X}, \mathrm{b}$ for $2 \mathrm{~h}$ of incubation at $4{ }^{\circ} \mathrm{C}$. After that, the supernatant was tested for ALP activity of the MG-63 cells by $p$ nitrophenyl phosphate ( $p$ NPP) and the ALP supplied by the kit as a standard. The absorbance of ALP was quantified at $405 \mathrm{~nm}$ by a microplate reader. The ALP activity was evaluated by using a Laboassay $^{\mathrm{TM}}$ ALP kit (Wako Pure Chemicals, Japan) based on the manufacturer's instructions. Results showed mean values of three individual tests.

\subsection{Statistical analysis}

Data for compressive strength, fracture toughness, weight loss in SBF, optical density of MTT and absorbance of ALP were presented as mean \pm standard deviation and statistically analyzed by using ANOVA (one-way analysis of variance). All the difference was deemed statistically significant at $p$-value less than 0.05 .

\section{Results and discussion}

\subsection{Scaffolds and phase identification}

A SrO doped scaffold $(18.5 \mathrm{~mm} \times 18.5 \mathrm{~mm} \times 6.5 \mathrm{~mm})$ fabricated by SLS was shown in Fig. 1a and b. Three-dimensional
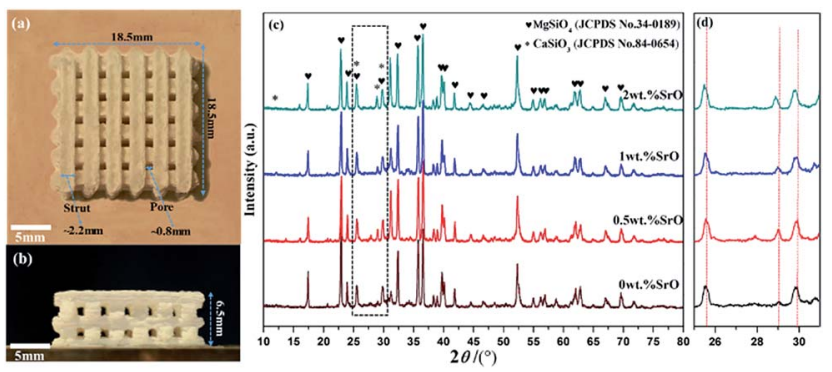

Fig. 1 The porous scaffold: (a) top view and (b) side view. And (c) XRD spectra and (d) magnified XRD spectra in the range of $2 \theta=25-31^{\circ}$

(3D) interconnected pores uniformly distributed throughout the whole scaffold. The 3D microchannels, comparing with $2 \mathrm{D}$ substrates, could provide an extensive spatial contact with the native extracellular matrix (ECM) after implantation, which was more favorable for nutrients transportation, bioactive elements release, and waste products excretion from the scaffolds. This was of great importance in facilitating cell proliferation, vascular ingrowth, and internal mineralized bone formation after implantation. ${ }^{36}$ Contrarily, $2 \mathrm{D}$ substrates only provide plane contact with ECM in which cell only surface anchored and the contact between neighboring cells was also limited to the flat edges. ${ }^{37}$ Therefore, the scaffolds with $3 \mathrm{D}$ architecture in this study were more favourable for bone regeneration.

The XRD spectra of the SrO doped and undoped biosilicates scaffolds were shown in Fig. 1c. A major phase of $\mathrm{Mg}_{2} \mathrm{SiO}_{4}$ and a second phase of $\beta-\mathrm{CaSiO}_{3}$ were detected. No significant diffraction peaks of SrO were detected due to the low amount of the SrO dopant. However, there was a slight shift in peak positions of $\beta-\mathrm{CaSiO}_{3}$ to lower $2 \theta$ value for doped scaffolds (Fig. 1d). This might because the substitution of the slightly larger ionic radius of $\mathrm{Sr}^{2+}(1.12 \AA)$ for $\mathrm{Ca}^{2+}(1.00 \AA)$ in the $\mathrm{CaSiO}_{3}$ lattice led to increase in the unit cell parameters.

\subsection{Microstructure and mechanical strength}

SEM micrographs of the scaffolds composed of distinct $\mathrm{Mg}_{2} \mathrm{SiO}_{4}$ grain appearance with the filling phase of $\mathrm{CaSiO}_{3}$ between $\mathrm{Mg}_{2} \mathrm{SiO}_{4}$ grains (Fig. 2a-d). EDS pointed analysis indicated that the strontium content in the filling phase was higher than that in the $\mathrm{Mg}_{2} \mathrm{SiO}_{4}$ phase (Fig. 2e and d). And EDS map showed that the distribution of Sr was consistent with the distribution of $\mathrm{Ca}$, which was opposite with the distribution of $\mathrm{Mg}$ (Fig. 3). Therefore, SrO was distributed in the filling phase as sintering additive. For the $0.5 \mathrm{SrO}$ scaffolds and $1 \mathrm{SrO}$ scaffolds, the filling phase slightly increased and the grain size of $\mathrm{Mg}_{2} \mathrm{SiO}_{4}$ decreased (Fig. 2b and c). The substitution of $\mathrm{Sr}^{2+}$ for $\mathrm{Ca}^{2+}$ in the $\mathrm{CaSiO}_{3}$ lattice led to the unit cell volume expansion and density decrease of $\mathrm{CaSiO}_{3}$, which would cause the expansion of the filling phase. While, for the $2 \mathrm{SrO}$ scaffolds, the further expanded filling phase led to the formation of loose continuous filling phase, which separated the $\mathrm{Mg}_{2} \mathrm{SiO}_{4}$ grains from each other (Fig. 2d).

The mechanical properties of the scaffolds were shown in Fig. 4. The compressive strength and fracture toughness 


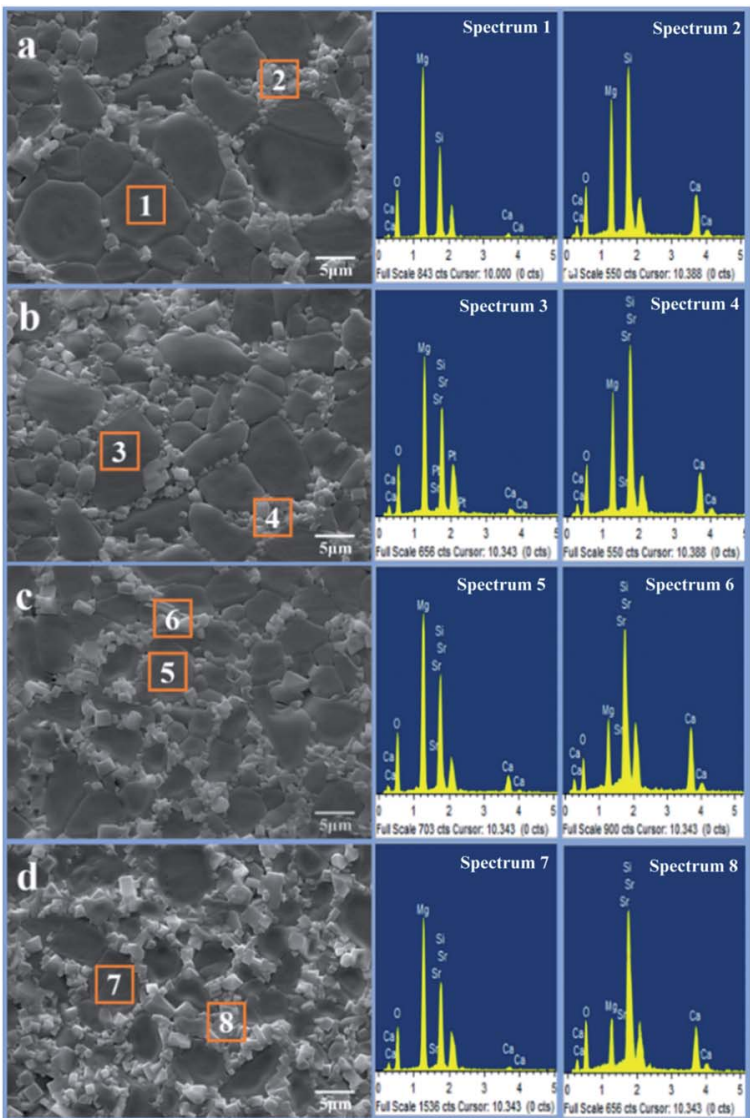

Fig. 2 SEM micrographs and EDS spectra of the (a) OSrO, (b) 0.5SrO, (c) $1 \mathrm{SrO}$, (d) $2 \mathrm{SrO}$ scaffolds.
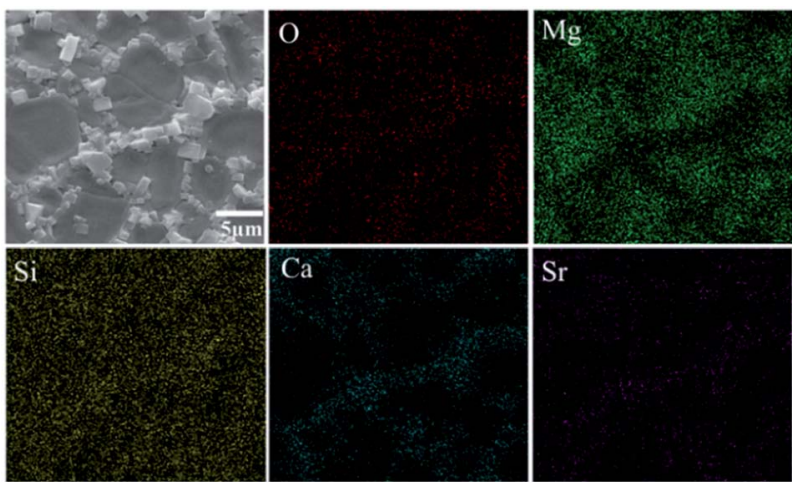

Fig. 3 Surface scanning analysis of the 1 SrO scaffolds.

remained stable as the SrO content increased from $0 \mathrm{wt} \%$ to 1.0 wt $\%$. The $0.5 \mathrm{SrO}$ scaffolds and 1 SrO scaffolds showed a similar dynamic stress-strain curve and approximate peak stress with the 0SrO scaffolds. The compressive strength and fracture toughness of the 1 SrO scaffolds reached $39.55 \pm 1.48 \mathrm{MPa}$ and $2.38 \pm 0.06 \mathrm{MPa} \mathrm{m}{ }^{1 / 2}$. While the mechanical strength obviously decreased when further increasing the SrO doping to $2.0 \mathrm{wt} \%$. The results were consistent with the above microstructure results. On one hand, SrO acted as sintering additive could promote densification and refine grain during the sintering
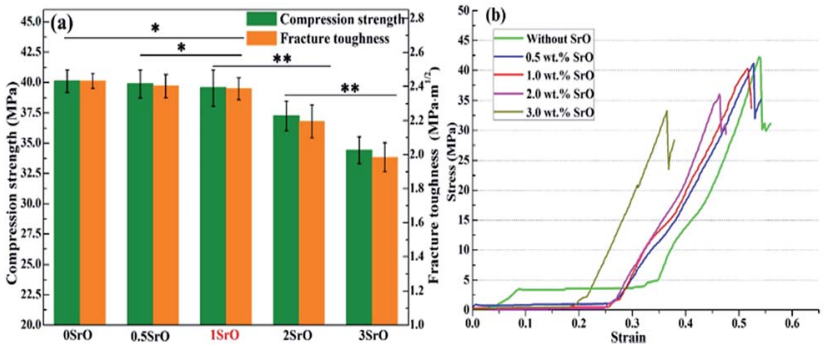

Fig. 4 (a) Compressive strength and fracture toughness of the scaffolds, and (b) stress-strain curves of compression strength test (error bars represent the standard deviation: $\left.{ }^{*} p>0.05, * *<0.05\right)$.

process (Fig. 2b). On the other hand, $\mathrm{Sr}^{2+}$ substituted for $\mathrm{Ca}^{2+}$ in the $\mathrm{CaSiO}_{3}$ lattice, which caused evident volume expansion and density decrease of the filling phase of $\mathrm{CaSiO}_{3}$ (Fig. 2c). This, in turn, will affect the filling effect and hinder the densification. Hence there were no significant influence on the strength and toughness of the scaffolds when the SrO content was within 1.0 wt\%. However, when SrO exceeded $1.0 \mathrm{wt} \%$, excess SrO distributed in the filling phase and more $\mathrm{Sr}^{2+}$ substituted for $\mathrm{Ca}^{2+}$ in the $\mathrm{CaSiO}_{3}$ lattice. As a consequence, a loose continuous filling phase was formed, which separated the $\mathrm{Mg}_{2} \mathrm{SiO}_{4}$ grains from each other and led to the decrease in densification and mechanical properties of the scaffolds (Fig. 2d). ${ }^{38}$

\subsection{Degradability and bioactivity}

For bone scaffolds, degradability is an indispensable capability to keep pace with the process of new bone formation. ${ }^{39}$ Both the SrO doped and undoped scaffolds constitutively degraded in SBF (Fig. 5). Their degradation rate slowed due to the apatite formation with the immersion time increased. The SrO doped scaffolds showed little more weight loss than that of undoped scaffolds after the same time of immersion. This might because the substitution of $\mathrm{Sr}^{2+}$ for $\mathrm{Ca}^{2+}$ in the $\mathrm{CaSiO}_{3}$ lattice led to unit cell volume expansion and the formation of a loose structure which promote the degradation of $\mathrm{CaSiO}_{3}$ in the scaffolds. Therefore, to some extent the $1 \mathrm{wt} \%$ SrO doping might slightly enhance the degradability.

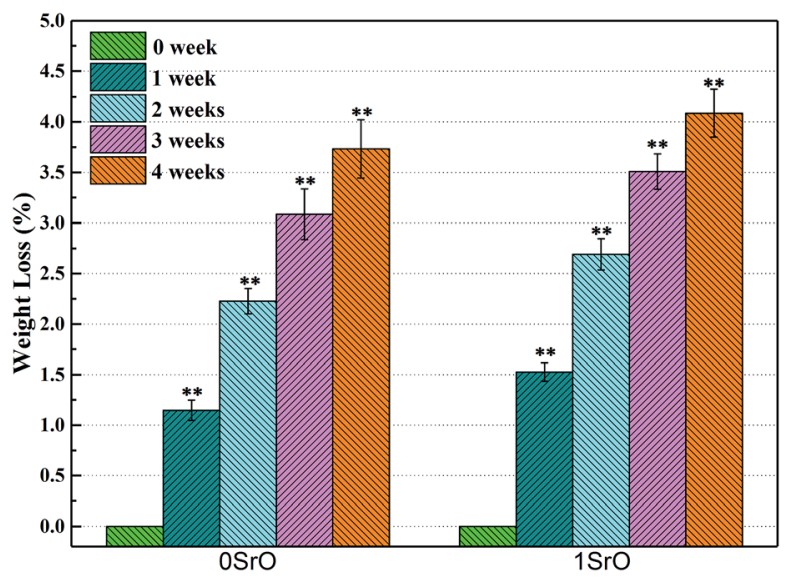

Fig. 5 Weight loss of $1 \mathrm{SrO}$ and $\mathrm{OSrO}$ scaffolds after soaking in SBF (**p $<0.05, n=5$ ). 


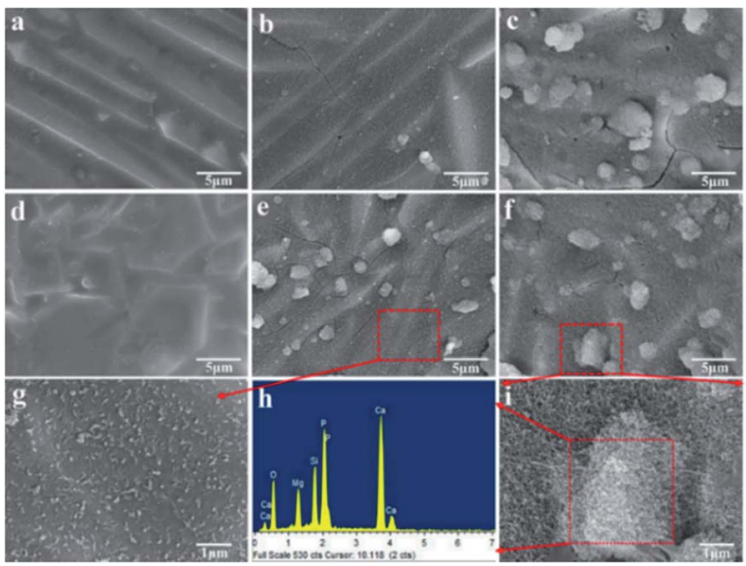

Fig. 6 SEM images of the $0 \mathrm{SrO}$ scaffolds $(a-c)$ and $1 \mathrm{SrO}$ scaffolds $(d-f)$ after immersion in SBF for 0 day ( $a$ and $d), 7$ days (b and e) and 14 days (c and f). And ( $g$ and i) high-magnification of (e and f), (h) EDS spectra of the selected region in (i).

The apatite formation on the $1 \mathrm{SrO}$ and $0 \mathrm{SrO}$ scaffolds after immersion in SBF was shown in Fig. 6. A lot of worm-like apatite particles formed on both the $1 \mathrm{SrO}$ and $0 \mathrm{SrO}$ scaffolds after 7 days of immersion (Fig. 6b-g). As the soaking time extended to 14 days, a dense sponge-like apatite layer fully covered on the scaffolds surface (Fig. 6c-i). Strong peaks of P (15.27 wt\%), Ca (26.21 wt\%) and O (43.99 wt\%) were detected (Fig. 6h), confirming that the sponge-like layer was apatite layer. Besides, new absorption bands correlated with the $\mathrm{O}-\mathrm{H}$ group $(2918$ and $2847 \mathrm{~cm}^{-1}$ ) and $\mathrm{P}-\mathrm{O}$ bending (1270 and $983 \mathrm{~cm}^{-1}$ ) in hydroxyapatite were detected after $1 \mathrm{SrO}$ scaffolds were soaked in SBF (Fig. 7).$^{40}$ The new band $\left(955 \mathrm{~cm}^{-1}\right)$ corresponding to $\mathrm{Si}-\mathrm{OH}$ was believed to play an important role in deposition and nucleation of apatite. ${ }^{41}$ The emerge of the bands of carbonate groups (1400-1580 $\mathrm{cm}^{-1}$ ) demonstrated the formation of hydroxycarbonate apatite. ${ }^{42}$ In addition, the XRD analysis of the immersed 1 SrO scaffolds showed that some typical diffraction

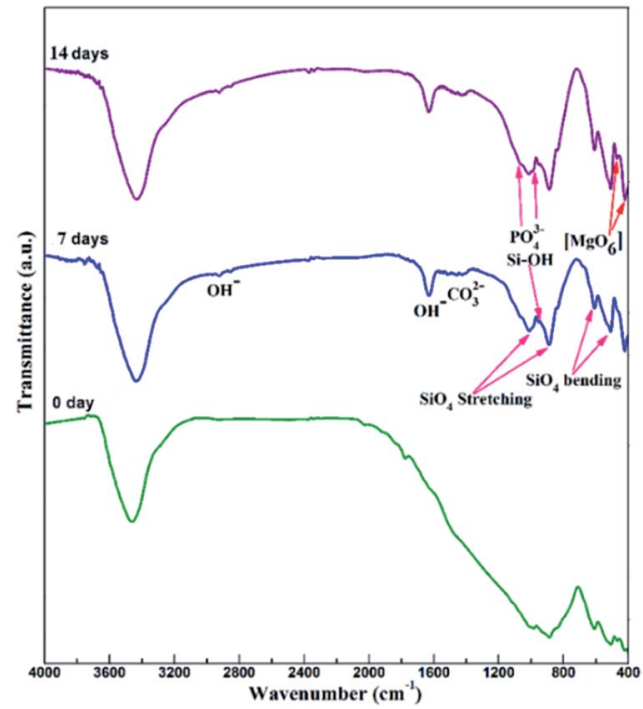

Fig. 7 FTIR spectra of the $1 \mathrm{SrO}$ scaffolds after soaking in SBF for 0, 7 and 14 days.

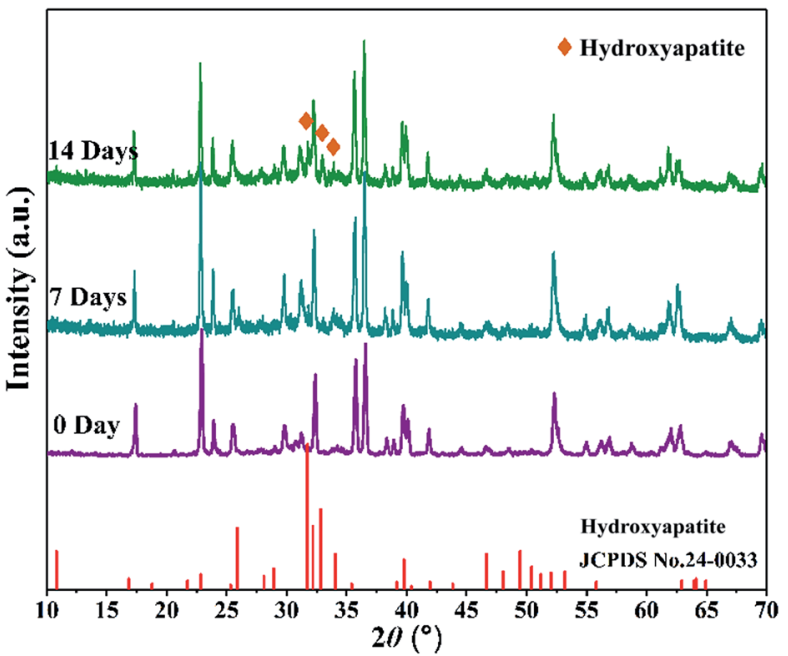

Fig. 8 XRD patterns of the $1 \mathrm{SrO}$ scaffolds after soaking in SBF for 0, 7 and 14 days.

peak at $31.8^{\circ}, 32.9^{\circ}$ and $34.0^{\circ}$ corresponding to apatite phase (JCPDS no. 24-0033) were detected and appeared to increase in intensity with prolonging immersion time (Fig. 8). This further confirmed the deposition of crystalline apatite phase on the 1 SrO scaffolds. These analysis results demonstrated that the SrO doped scaffolds possessed good apatite formability.

The bone-like apatite can biologically bond with living bone tissue, which can forecast the in vivo bone bioactivity of the scaffolds. This apatite formation mechanism in SBF was summarized in Fig. 9 and can be described as follows: ${ }^{\mathbf{4 3 , 4 4}}$

Stage 1: dissolution of $\mathrm{CaSiO}_{3}$ in $\mathrm{SBF}$ gave rise to rapid exchange of released $\mathrm{Ca}^{2+}$ with $\mathrm{H}_{3} \mathrm{O}^{+}$or $\mathrm{H}^{+}$from the solution.

$$
\mathrm{CaSiO}_{3}+\mathrm{H}_{2} \mathrm{O} \rightarrow \mathrm{HSiO}_{3}{ }^{-}+\mathrm{Ca}^{2+}+\mathrm{OH}^{-}
$$

Stage 2: with the degradation of $\mathrm{CaSiO}_{3}$, loss of soluble silica in the form of $\mathrm{Si}(\mathrm{OH})_{4}$ in the solution, resulting from breaking of $\mathrm{Si}-\mathrm{O}-\mathrm{Si}$ bonds and formation of $\mathrm{Si}-\mathrm{OH}$ (silanol group) at the scaffold interface.

$$
\mathrm{Si}-\mathrm{O}-\mathrm{Si}+\mathrm{H}_{2} \mathrm{O} \rightarrow \mathrm{Si}-\mathrm{OH}+\mathrm{HO}-\mathrm{Si}
$$

Stage 3: polycondensation of silanol groups formed hydrated silica gel. This also led to the depletion of alkalis cations.

Stage 4: the hydrated silica gel layer was negatively charged and could adsorb $\mathrm{Ca}^{2+}$ and $\mathrm{PO}_{4}{ }^{3-}$ in the solution. Meanwhile, the $\mathrm{Ca}^{2+}$ and $\mathrm{OH}^{-}$ions on dissolved surface continually increased to exceed the solubility of the apatite in SBF. Both the factors enhanced the driving force to induce the nucleation of amorphous calcium phosphate.

$$
10 \mathrm{Ca}^{2+}+6 \mathrm{HPO}_{4}^{2-}+8 \mathrm{OH}^{-} \rightarrow \mathrm{Ca}_{10}\left(\mathrm{PO}_{4}\right)_{6}(\mathrm{OH})_{2}+6 \mathrm{H}_{2} \mathrm{O}
$$

Stage 5: the apatite crystallized from amorphous phase to stable phases and then spontaneously grew into apatite layer. 


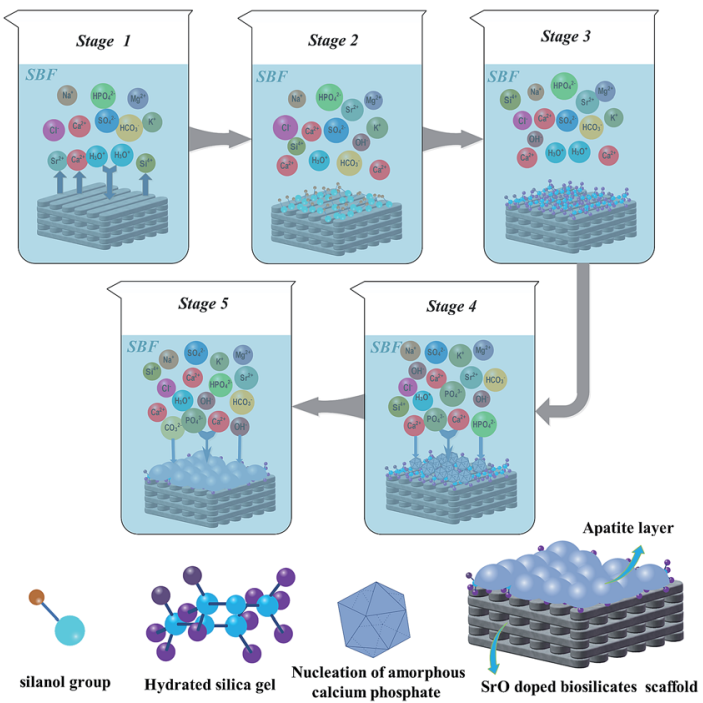

Fig. 9 Apatite formation mechanism in SBF of $\mathrm{SrO}$ doped biosilicates scaffolds.

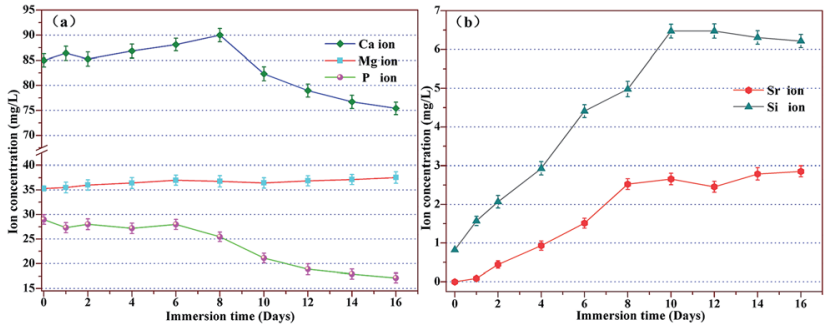

Fig. 10 Ion concentration in SBF after soaking the $1 \mathrm{SrO}$ doped scaffolds for various time periods.

Additionally, some carbonate-substituted hydroxyapatite formed due to the substitution of $\mathrm{PO}_{4}{ }^{3-}$ or $\mathrm{OH}^{-}$ions with the $\mathrm{CO}_{3}{ }^{2-}$ ions.

The corresponding variation of ion concentrations $(\mathrm{Sr}, \mathrm{Ca}$, $\mathrm{Mg}, \mathrm{P}$, and $\mathrm{Si}$ ions) in SBF (without $\mathrm{Sr}$ ion) after soaking the $1 \mathrm{SrO}$ scaffolds for various time periods was shown in Fig. 10. The release of $\mathrm{Sr}$ ion showed sustained release kinetics without burst release which followed by a near steady state $(2.0-3.0 \mathrm{mg}$ $\mathrm{L}^{-1}$ ). The release of $\mathrm{Sr}$ ions derived from the dissolution of $\mathrm{SrO}$ $\left(\mathrm{Sr}(\mathrm{OH})_{2}\right)$ and $\mathrm{Sr}$-substituted $\mathrm{CaSiO}_{3}$ in the filling phase of the scaffolds. Besides, with the dissolution of $\mathrm{CaSiO}_{3}, \mathrm{Ca}$ ions increased at the first week showing the rapid ion exchange between the scaffolds and SBF at first stage of apatite formation, whereas the $\mathrm{Mg}$ ions showed a slight increase throughout the whole soaking process due to the poor solubility of $\mathrm{Mg}_{2} \mathrm{SiO}_{4}$ than that of $\mathrm{CaSiO}_{3}$. Moreover, sustained increase of $\mathrm{Si}$ ion concentration at the end of the 10th day showing the formation of soluble silica in the form of $\mathrm{Si}(\mathrm{OH})_{4}$ at the second stage of apatite formation. And the stagnation of the increase of Si ion concentration around day 10 to day 16 showed the polycondensation of silanol groups at the third stage of apatite formation. It was noted that a simultaneous decrease of $\mathrm{Ca}$ and $\mathrm{P}$ ions concentration at second week proved the nucleation of the amorphous calcium phosphate (ACP) at the fourth and the final formation of the apatite layer at the fifth stage. This was also consistent with the above results in which apatite particles formed after 7 days of immersion (Fig. 6b-g) and dense apatite layer covered on the scaffolds surface after 14 days of immersion (Fig. 6c-i). Summarizing, the variation of ions concentration $(\mathrm{Ca}, \mathrm{Si}$, and $\mathrm{P})$ in SBF strongly supported the formation process of apatite (Fig. 6 and 9), this further verified the bioactivity of the SrO doped scaffolds.

\subsection{Cell-scaffold interactions}

MG-63 cells cultured on the scaffolds were imaged to investigate cell attachment, growth and spreading (Fig. 11). The 1SrO scaffolds showed a better cell adhesion than that of $0 \mathrm{SrO}$ scaffolds after one day of culture. After three days of culture, cells on the $1 \mathrm{SrO}$ scaffolds exhibited a round shape with abundant lamellipodia and filopodia extensions. And these cellular extensions tended to extend to neighboring cells, indicating strong attachment to the substrate and good intercellular interaction. While, the cells on 0SrO scaffolds exhibited fewer filopodia, showing poor cell spreading and intercellular connections. After five days, confluent cells layers with rough surface covered on the entire surface of the $1 \mathrm{SrO}$ scaffolds, suggesting multilayer proliferation of MG-63 cells. In contrast, less area of 0SrO scaffolds surface was covered by confluent cells layers.

Fluorescent images of live cells through staining after culture for different time were shown in Fig. 12. The live cells were fusiform shape, suggesting normal cell growth. After one day of culture, more cells attached on the $1 \mathrm{SrO}$ scaffolds than that of 0SrO scaffolds. Three days later, cells on the $1 \mathrm{SrO}$ scaffolds developed abundant lamellipodia and filopodia to extend to nearby cells. And on day five, a higher number of cells covered on the 1 SrO scaffolds than 0SrO scaffolds due to active cell proliferation and intercellular interaction. The cell morphology and fluorescence images indicated that the SrO doping might improve the adhesion and growth of the MG-63 cells.

To quantitatively determine the cell proliferation, the MTT assay study also has been carried out on both $1 \mathrm{SrO}, 0.5 \mathrm{SrO}$ and 0SrO scaffolds. As shown in Fig. 13, cell proliferation was evident on both the $1 \mathrm{SrO}$ and $0 \mathrm{SrO}$ scaffolds over the duration of the experiment compared with the blank group. Obviously, 1 SrO scaffolds showed the highest cell proliferation, in which

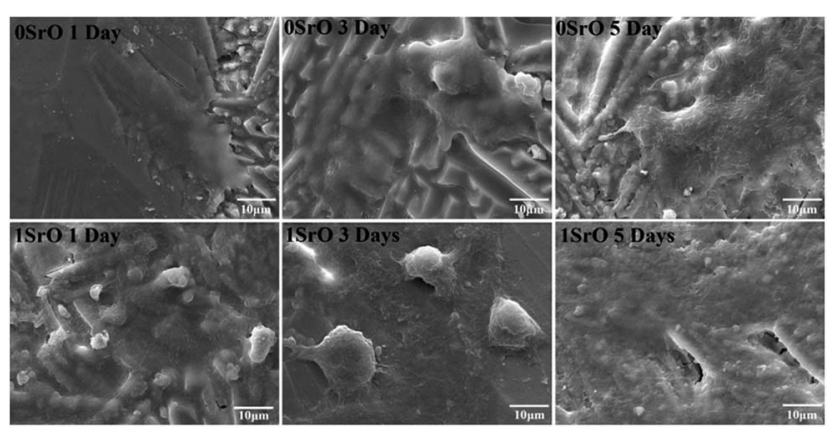

Fig. 11 Cell attachment and proliferation on the $1 \mathrm{SrO}$ and $0 \mathrm{SrO}$ scaffolds after 1, 3 and 5 days of culture. 


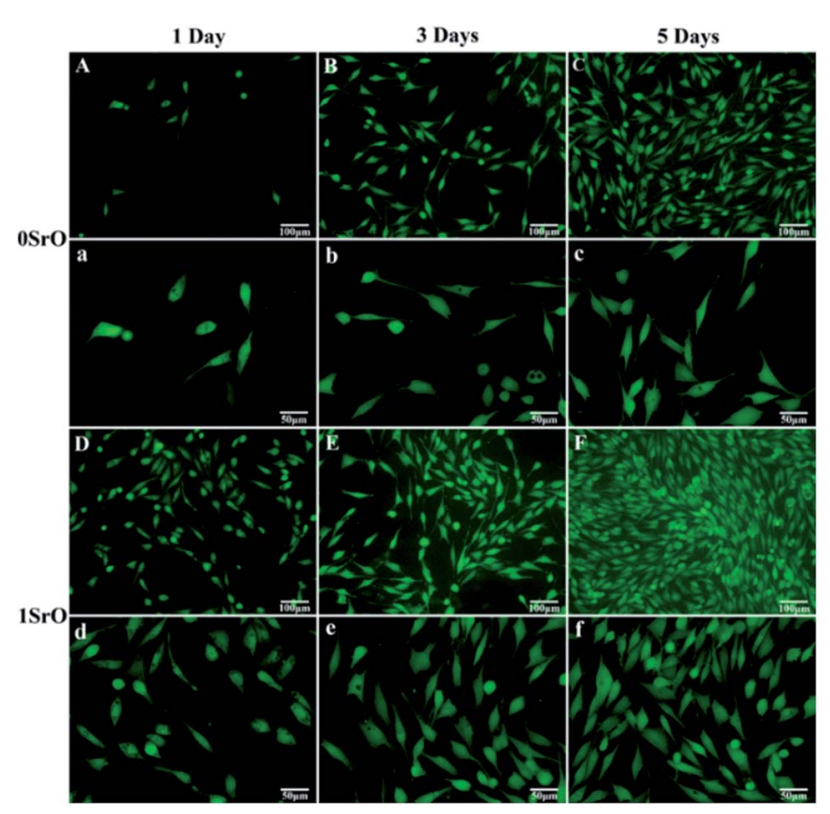

Fig. 12 Fluorescence microscopy images of the MG-63 cells cultured on $((A-C)$ and $(a-c)) 0 S r O$ scaffolds and $((D-F)$ and $(d-f)) 15 r O$ scaffolds for 1,3 and 5 days.

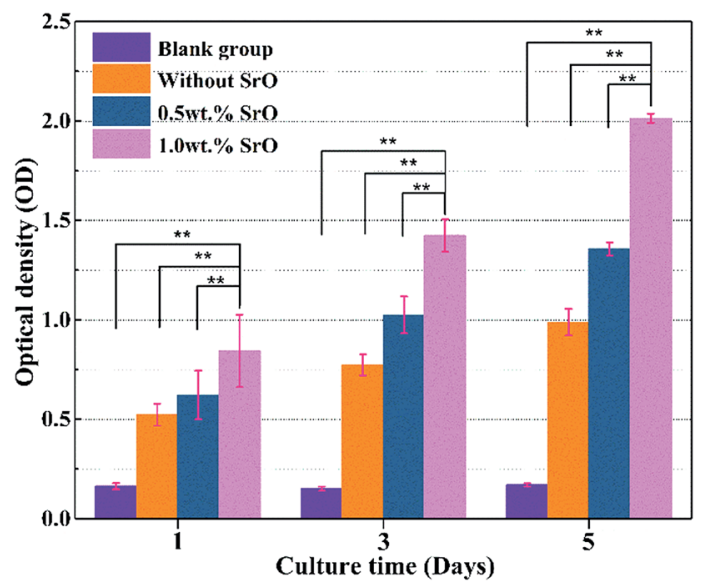

Fig. 13 MTT assay for OSrO, 0.5SrO and $1 \mathrm{SrO}$ scaffolds after 1,3 and 5 days of culture $(n=3, * * p<0.05)$.

cell density increased approximately $140 \%$ after five days of culture compared with one day of culture. And cell viability and proliferation on $1 \mathrm{SrO}$ scaffolds was significantly higher (approximately twice and 1.5 times on OD value, respectively) than that on $0 \mathrm{SrO}$ and $0.5 \mathrm{SrO}$ scaffolds after five days of culture. These results indicated the beneficial effects of SrO on promoting cell proliferation.

Owing to ALP expression was related to early cell differentiation, the differentiation of MG-63 cell on the $1 \mathrm{SrO}$ and $0 \mathrm{SrO}$ scaffolds was also investigated by ALP staining after culture. As shown in Fig. 14, the cells cultured on the 1 SrO scaffolds presented highly intensive ALP staining as compared with the OSrO after three and five days of culture. Moreover, it was clear that the cells cultured on the $1 \mathrm{SrO}$ scaffolds showed affluent well-

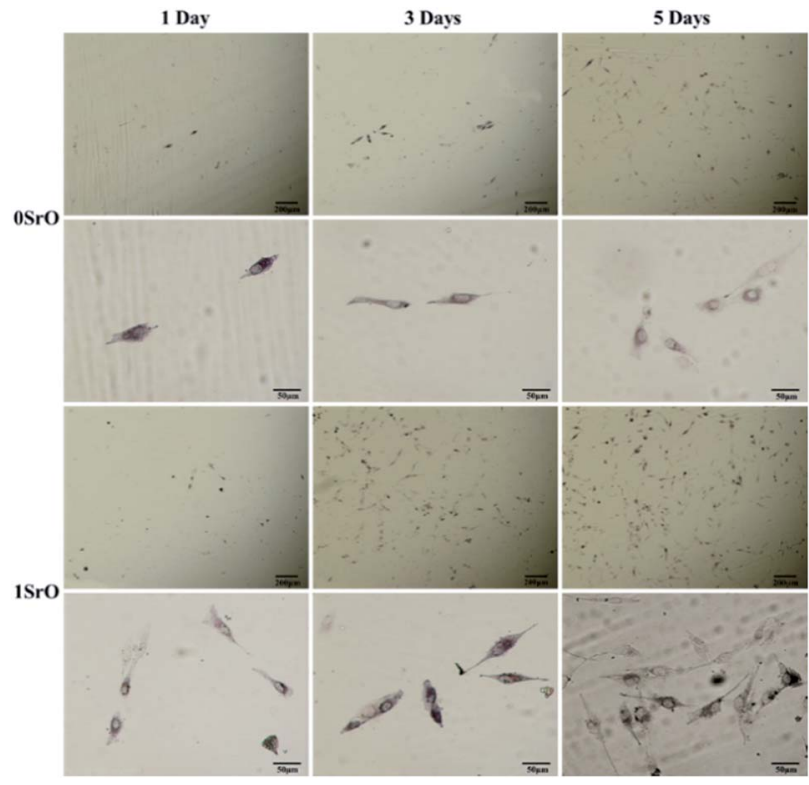

Fig. 14 ALP staining images of the MG- 63 cells after cultured on OSrO and $1 \mathrm{SrO}$ scaffolds for 1,3 and 5 days.

developed filopodia which extended to the neighboring cell. Cell differentiation ability was also assessed by quantitatively measuring the ALP activity of MG-63 cells (Fig. 15). Both 1 SrO and 0.5SrO scaffolds showed a significantly enhanced ALP expression as the prolonging of immersion time, in which ALP activity increased approximately $150 \%$ after five days of culture compared with one day of culture. And the ALP activity on $1 \mathrm{SrO}$ scaffolds was also significantly higher (approximately $177 \%$ and $135 \%$ at fifth day, respectively) than that on $0 \mathrm{SrO}$ and $0.5 \mathrm{SrO}$ scaffolds. These results revealed that introduction of SrO promoted the ALP expression of the MG-63 cells, indicating significantly improved differentiation ability with the increasing of SrO content in the scaffolds.

For bone scaffolds, favorable cellular responses like cell adhesion, proliferation and differentiation were crucial for realizing bone repair and regeneration. ${ }^{45}$ The above cell culture studies demonstrated that $\mathrm{SrO}$ doping in $\mathrm{Mg}_{2} \mathrm{SiO}_{4} / \mathrm{CaSiO}_{3}$ scaffolds did effectively enhance cell adhesion, proliferation and differentiation toward faster bone tissue regeneration. This could be attributed to the dual effect of $\mathrm{Sr}^{2+}$ on stimulating osteoblast-related gene expression and inhibiting osteoclasts differentiation. Some researches showed that strontium could activate multiple signaling pathways in bone cells. Notably, activation of the calcium sensing receptor (CaSR) and the indicated downstream pathways such as (NFATc)/Wnt signaling and fibroblast growth factor receptor (FGFR) which would promote osteoblastogenesis (ALP, type I collagen and osteocalcin, etc.) expression and bone formation. ${ }^{46,47}$ For example, Marie et al. studied the actions of strontium on bone metabolism and demonstrated that strontium modulates bone cell recruitment and activity through modulation of the CaSR, ERK1/2-MAPK and NFATc/Wnt signaling pathways. ${ }^{48}$

Also, the effects of $\mathrm{Sr}^{2+}$ on cell behaviours were dosedependent. In this study, the Sr ion concentration released 


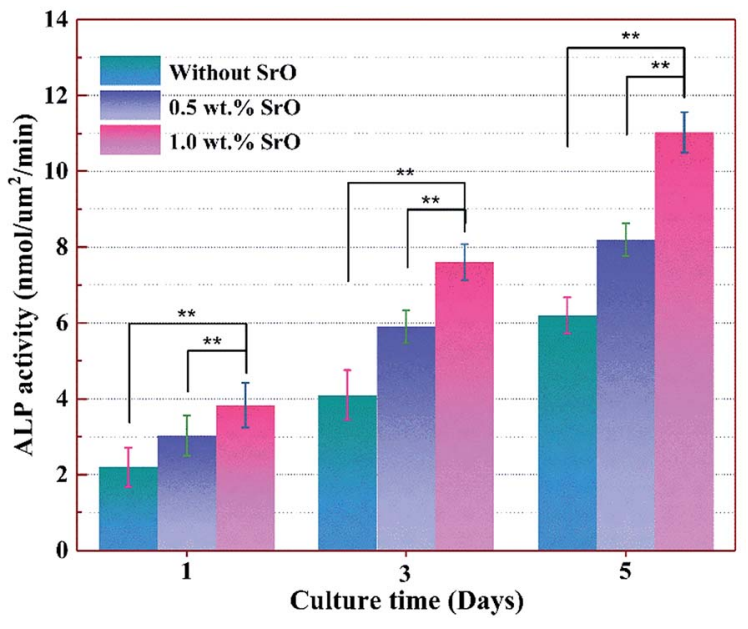

Fig. 15 ALP activity of MG- 63 cells on $0 \mathrm{SrO}, 0.5 \mathrm{SrO}$ and $1 \mathrm{SrO}$ scaffolds at various time points $(n=3, * * p<0.05)$.

from the $1 \mathrm{SrO}$ scaffolds in SBF increased linearly at a rate of about $0.5 \mathrm{mg} \mathrm{L}^{-1} \mathrm{~d}^{-1}$ at the first week, and up to $2.526 \mathrm{mg} \mathrm{L}^{-1}$ at the eighth day. After that, the $\mathrm{Sr}$ ion concentration reached a relatively stable level (Fig. 10). Summarily, the release of $\mathrm{Sr}$ ions in SBF showed sustained release kinetics without burst release and afterwards reached a near steady state $(2.0-3.0 \mathrm{mg}$ $\mathrm{L}^{-1}$ ), thereby heralding long-term sustainable release. E. Canalis et al. found that osteoblast precursor proliferation and extracellular matrix proteins expression were stimulated in the presence of about $10^{-3} \mathrm{mM} \mathrm{Sr}^{2+} .^{9} \mathrm{~S}$. C. Verberckmoes et al. found that osteoblast-mediated bone formation was improved by about $2.0-5.0 \mu \mathrm{g} \mathrm{mL} \mathrm{m}^{-1}\left(2.3-5.7 \times 10^{-3} \mathrm{mM}\right) \mathrm{Sr}^{2+} .{ }^{50}$ The toplimit of Sr ions concentration released from the scaffolds in SBF (2.85 $\mathrm{mg} \mathrm{L}^{-1}$ ) was within the above reported safety level of $\mathrm{Sr}$ ions. The results indicated that the SrO doped scaffolds in this study could steadily release $\mathrm{Sr}$ ions at a safety level and effectively stimulate cell proliferation and differentiation.

In addition to the Sr-mediated stimulation of the cell response, $\mathrm{Si}$ and $\mathrm{Ca}$ ions released with the degradation of the scaffolds could also influence the cell behavior. It was reported that $\mathrm{Si}$ and $\mathrm{Ca}$ ions were beneficial to the proliferation and differentiation of bone-forming cells..$^{51,52}$ Meanwhile, they also played a crucial role in the formation of bioactive bone-like apatite. Such bone-like apatite could provide a favorable environment for promoting cell adhesion to the scaffolds due to its similar chemical compositions to that of natural bone. ${ }^{53}$ As expected, cells exhibited favourable adhesion and proliferation behaviours on the scaffolds compared with the blank group. Notably, the SrO doped scaffolds showed effectively enhanced cell adhesion, proliferation and ALP activity. Therefore, the good biological effects could be the synergistic stimulation of these bioactive ions.

\section{Conclusions}

SrO effectively improved biological properties of the biosilicates scaffolds via promoting cell attachment, proliferation, and differentiation. Moreover, SrO doped scaffolds continuously degraded and formed dense bone-like apatite layer in SBF. Besides, the doped scaffolds obtained a stable mechanical strength. Their compressive strength and fracture toughness reached $39.55 \pm 1.48 \mathrm{MPa}$ and $2.38 \pm 0.06 \mathrm{MPa} \mathrm{m}^{1 / 2}$, respectively. Therefore, this study indicated that the SrO doped biosilicates scaffolds would be a promising candidate for bone repair/regeneration.

\section{Acknowledgements}

This work was supported by the following funds: (1) The Natural Science Foundation of China (51575537, 81572577); (2) Overseas, Hong Kong \& Macao Scholars Collaborated Researching Fund of National Natural Science Foundation of China (81428018); (3) Hunan Provincial Natural Science Foundation of China (14JJ1006, 2016JJ1027); (4) The Project of Innovationdriven Plan of Central South University (2015CXS008, 2016CX023); (5) The Open-End Fund for the Valuable and Precision Instruments of Central South University; (6) The fund of the State Key Laboratory of Solidification Processing in NWPU (SKLSP201605); (7) The fund of the State Key Laboratory for Powder Metallurgy; (8) The Fundamental Research Funds for the Central Universities of Central South University. (9) The Project of State Key Laboratory of High Performance Complex Manufacturing, Central South University (ZZYJKT2017-05).

\section{References}

1 S. Y. Ni, L. Chou and C. Jiang, Ceram. Int., 2007, 33, 83-88.

2 M. Kharaziha and M. H. Fathi, Ceram. Int., 2009, 35, 24492454.

3 H. Ghomi, M. Jaberzadeh and M. H. Fathi, J. Alloys Compd., 2011, 509, 1382-1394.

4 M. H. Fathi and M. Kharaziha, Int. J. Mod. Phys. B, 2012, 22, 3082-3091.

5 C. Wu and J. Chang, Biomed. Mater., 2013, 8, 032001.

6 F. Tavangarian and R. Emadi, Ceram. Int., 2011, 37, 22752280.

7 J. J. Deng, P. J. Li, C. D. Gao, P. Feng, C. J. Shuai and S. P. Peng, Mater. Manuf. Processes, 2014, 29, 877-884.

8 S. K. Padmanabhan, F. Gervaso, M. Carrozzo, F. Scalera, A. Sannino and A. Licciulli, Ceram. Int., 2013, 39, 619-627.

9 K. L. Lin, M. L. Zhang, W. Y. Zhai, H. Y. Qu and J. Chang, J. Am. Ceram. Soc., 2011, 94, 99-105.

10 S. Y. Ni and J. Chang, J. Biomater. Appl., 2009, 24, 139-158. 11 S. Y. Ni, C. Jiang and L. Chou, J. Mater. Sci.: Mater. Med., 2008, 19, 359-367.

12 P. Habibovic and J. E. Barralet, Acta Biomater., 2011, 7, 30133026.

13 A. Byopadhyay, S. Bernard, W. C. Xue and S. Bose, J. Am. Ceram. Soc., 2006, 89, 2675-2688.

14 S. Bodhak, S. Bose and A. Bandyopadhyay, J. Am. Ceram. Soc., 2011, 94, 1281-1288.

15 D. D. Hu, L. Kai, Y. T. Xie, H. H. Pan, J. Zhao, L. P. Huang and X. B. Zheng, J. Mater. Sci.: Mater. Med., 2016, 27, 1-13. 
16 J. H. Zhang, S. C. Zhao, Y. F. Zhu, Y. J. Huang, Z. Min, C. L. Tao and C. Q. Zhang, Acta Biomater., 2014, 10, 22692281.

17 W. Querido, A. L. Rossi and M. Farina, Micron, 2015, 80, 122134.

18 L. G. Xia, N. Zhang, X. H. Wang, Y. N. Zhou, L. X. Mao, J. Q. Liu, X. Q. jiang, Z. Y. Zhang, J. Chang, K. L. Lin and B. Fang, J. Mater. Chem. B, 2016, 4, 3313-3323.

19 W. B. Zhang, Y. H. Shen, H. B. Pan, K. L. Lin, X. G. Liu, B. W. Darvell, W. W. Lu, L. F. Deng, D. P. Wang, W. H. Huang and J. Chang, Acta Biomater., 2011, 7, 800-808.

20 K. L. Lin, L. G. Xia, H. Y. Li, X. Q. Jiang, H. B. Pan, Y. J. Xu, W. W. Lu, Z. Y. Zhang and J. Chang, Biomaterials, 2013, 34, 10028-10042.

21 K. L. Lin, X. H. Wang, N. Zhang and Y. H. Shen, J. Mater. Chem. B, 2016, 4, 3632-3638.

22 E. Gentleman, Y. C. Fredholm, G. Jell, N. Lotfibakhshaiesh, M. D. O'Donnell and R. G. Hill, Biomaterials, 2010, 31, 3949-3956.

23 M. D. O'Donnell, P. L. Candarlioglu, C. A. Miller, E. Gentleman and M. M. Stevens, J. Mater. Chem., 2010, 20, 8934-8941.

24 K. Devoe, S. Banerjee, M. Roy, A. Bandyopadhyay and S. Bose, J. Am. Ceram. Soc., 2012, 95, 3095-3102.

25 G. X. Ni, J. H. Lin, P. K. Y. Chiu, Z. Y. Li and W. W. Lu, J. Mater. Sci.: Mater. Med., 2010, 21, 377-384.

26 D. S. Oh, Y. H. Kim, D. Ganbat, M. H. Han, P. Lim, J. H. Back, F. Y. Lee and H. Tawfeek, Ceram. Int., 2013, 39, 8401.

27 L. H. Han, S. Yu, T. Y. Wang, A. W. Behn and F. Yang, Adv. Funct. Mater., 2013, 23, 346-358.

28 R. Akbarzadeh and A. M. Yousefi, J. Biomed. Mater. Res., Part $B, 2014,102,1304-1315$.

29 T. Y. Young, J. M. Lee, S. Y. Yoon and H. C. Park, J. Mater. Sci.: Mater. Med., 2010, 21, 1495-1502.

30 S. Y. Ni, J. Chang and L. Chou, J. Biomed. Mater. Res., Part A, 2006, 76, 196-205.

31 S. F. S. Shirazi, S. Gharehkhani, M. Mehrali, H. Yarmand, H. S. C. Metselaar, N. A. Kadri and N. A. A. Osman, Sci. Technol. Adv. Mater., 2015, 16, 033502.

32 S. Eshraghi and S. Das, Acta Biomater., 2010, 6, 2467.

33 Y. W. Yang, P. Wu, X. Lin, Y. Liu, H. Bian, Y. Z. Zhou, C. D. Gao and C. J. Shuai, Virtual and Physical Prototyping, 2016, 1-9.
34 S. Hayashi-Sakai, J. Sakai, M. Sakamoto and H. Endo, J. Mater. Sci.: Mater. Med., 2012, 23, 2047-2054.

35 T. Kokubo and H. Takadama, Biomaterials, 2006, 27, 29072915.

36 Y. F. Zhang, W. Fan, Z. C. Ma, C. T. Wu, W. Fang, G. Liu and Y. Xiao, Acta Biomater., 2010, 6, 3021-3028.

37 E. Santos, R. M. Hernández, J. L. Pedraz and G. Orive, Trends Biotechnol., 2012, 30, 331-341.

38 H. Sun, S. W. He, P. Wu, C. D. Gao, P. Feng, T. Xiao, Y. W. Deng and C. J. Shuai, Materials, 2016, 9, 287.

39 N. Boehnke, C. Cam, E. Bat, T. Segura and H. D. Maynard, Biomacromolecules, 2015, 16, 2101-2108.

40 K. P. Ananth, A. J. Nathanael, S. P. Jose, T. H. Oh and D. Mangalaraj, Mater. Sci. Eng., C, 2015, 59, 1110-1124.

41 C. Berbecaru, H. V. Alexandru, G. E. Stan, D. A. Marcov, I. Pasuk and A. Ianculescu, Mater. Sci. Eng., B, 2010, 169, 101-105.

42 S. Bose, S. Tarafder, S. S. Banerjee, N. M. Davies and A. Bandyopadhyay, Bone, 2011, 48, 1282-1290.

43 I. Izquierdo-Barba, D. Arcos, Y. Sakamoto, O. Terasaki, A. López-Noriega and M. Vallet-Regí, Chem. Mater., 2008, 20, 3191-3198.

44 L. L. Hench, J. Am. Ceram. Soc., 1991, 74, 1487-1510.

45 K. M. Pang, J. K. Lee, Y. K. Seo, S. M. Kim, M. J. Kim and J. H. Lee, Bio-Med. Mater. Eng., 2015, 25, 25-38.

46 S. Bose, G. Fielding, S. Tarafder and A. Bandyopadhyay, Trends Biotechnol., 2013, 31, 594-605.

47 K. L. Lin, P. Y. Liu, L. Wei, Z. Y. Zou, W. B. Zhang, Y. Qian, Y. H. Shen and J. Chang, Chem. Eng. J., 2013, 222, 49-59.

48 Z. Saidak and P. J. Marie, Pharmacol. Ther., 2012, 136, 216226.

49 E. Canalis, M. Hott, P. Deloffre, Y. Tsouderos and P. J. Marie, Bone, 1996, 18, 517-523.

50 S. C. Verberckmoes, M. E. D. Broe and P. C. D'Haese, Kidney Int., 2013, 64, 534-543.

51 P. Valerio, M. M. Pereira, A. M. Goes and M. F. Leitea, Biomaterials, 2004, 25, 2941-2948.

52 A. Z. Alshemary, A. E. Pazarceviren, A. Tezcaner and Z. Evis, RSC Adv., 2016, 6, 68058-68071.

53 F. M. Zhang, J. Chang, J. X. Lu and C. Q. Ning, Mater. Sci. Eng., C, 2008, 28, 1330-1339. 